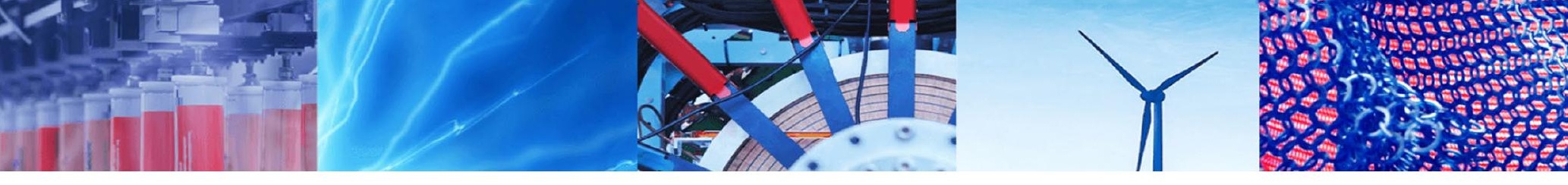

Research Article

\title{
Electrical, mechanical, and thermal characteristics of nonwoven fabric heating sheets containing chopped carbon fibers
}

\author{
Ji Yeon Kim ${ }^{1,2}$ (D) So Ra Lee ${ }^{3}$ (D) Gyo Woo Lee ${ }^{3}$ (D) Dae Hee Park ${ }^{2}$ (D) Kay Hyeok An ${ }^{4}$ (D) Won-Seok Kim ${ }^{1}$ (D)
}

Received: 3 February 2020 / Accepted: 4 June 2020 / Published online: 17 July 2020

(c) Springer Nature Switzerland AG 2020

\begin{abstract}
Discontinuous carbon fiber (CF) composite materials have potential as heating elements, but the practical realization of heat-generating characteristics has been restricted by the high resistance of conventional CF composites. In this study, the electrical, mechanical, and thermal properties of heating sheets with discontinuous CFs were investigated. The properties were found to vary depending on CF length and the dispersant content. Sheets containing CFs $6 \mathrm{~mm}$ in length and 16.9-45.8 wt\% dispersant showed optimum electrical and mechanical properties for heating elements. The CF heating sheets showed a low volume resistivity and a high glass transition temperature. The far-infrared emissivity of the CF heating sheets corresponded to $90 \%$ of that of a black body and was higher than that of a nichrome wire. Internal energy saturation of the CF heating sheets occurred within $5 \mathrm{~s}$ owing to low heat capacity. These features indicate that the CF heating sheets are suitable for application as a portable heating element.
\end{abstract}

Keywords Heating sheets · Chopped carbon fiber · Heat radiation efficiency · Mechanical properties · Electrical properties

\section{Introduction}

The planar heating element can reduce power consumption by 20 to $40 \%$, because it can transmit heat uniformly without a heat diffusion layer, while the linear heating element uses such a layer to spread locally generated heat [1]. As the heating material used for the linear heating element, metals such as tungsten, nichrome, and silverplated copper are used, mainly used as heating wires for household heaters [2, 3]. However, despite heat treatment to improve the mechanical properties, the metal wires disconnect easily, causing a decrease in strength with repetition bending. Such disconnections have caused fires due to hot-spot occurrence [4]. On the other hand, the planar heating element composed of a carbon material has high resistance to breakage against external forces because of the strength of many connected carbon particles.

In particular, since the carbon material emits far infrared rays in the wavelength range of $8-16 \mu \mathrm{m}$, which are beneficial to the human body, interest in a heating element using a carbon material is increasing $[5,6]$.

Carbon black of carbonaceous materials has been widely used in planar heating elements owing to its high durability against heat, high thermal conductivity, low thermal expansion coefficient, lightweight, and low manufacturing cost. However, carbon-black heating

Ji Yeon Kim and So Ra Lee have contributed equally to this work.

Kay Hyeok An; $\bowtie$ Won-Seok Kim, kimws1210@kctech.re.kr; Ji Yeon Kim, dbsk08@kctech.re.kr| ${ }^{1}$ Korea Institute of Carbon Convergence Technology, Jeonju, Jeonbuk 54852, Republic of Korea. ${ }^{2}$ Division of Information and Communication Engineering, Wonkwang University, Iksan, Jeonbuk 54538, Republic of Korea. ${ }^{3}$ Division of Mechanical Design Engineering, Chonbuk National University, Jeonju, Jeonbuk 54896, Republic of Korea. ${ }^{4}$ Division of Carbon and Nano Materials Engineering, Jeonju University, Jeonju, Jeonbuk 55069, Republic of Korea. 
elements are restricted by several issues, such as high electrical resistivity resulting from low crystallinity, a high percolation threshold for electrical conductivity owing to a small aspect ratio, and large changes in resistance with mechanical bending [7]. To overcome the limitations of carbon-black-based heating elements, carbon nanotubes (CNTs), which have high aspect ratios and high crystallinities, have been proposed as materials for heating sheets $[8,9]$. However, the high manufacturing cost of CNTs remains a major hindrance for commercialization of CNT-based heating elements.

The planar heating element based on CFs can solve the problems of graphite and CNTs heating sheets [10]. $\mathrm{CF}$ is a continuous fiber in which thousands of fine fibers of $7 \mu \mathrm{m}$ in diameter are aggregated in one direction. T-700 grade CF is particularly suitable for use as a heating material, because it has a tensile strength of $4.9 \mathrm{GPa}$, an electrical conductivity of $625 \mathrm{~S} \mathrm{~cm}^{-1}$, a density of $1.86 \mathrm{~g} \mathrm{~cm}^{-3}$, and thermochemical stability [11-15].

The research of CF heating sheets has been advanced by the combination of CFs and polymers (dispersion material and binder). In previous studies, polyvinyl alcohol (PVA), epoxy, polypropylene (PP), etc., have been used as additives, and chopped CFs have been used to reduce manufacturing costs $[16,17]$. The heating temperature of CF sheets with short CFs increased as voltage application time increased, and the energy conversion efficiency reached $100 \%$, while the heating rate was as low as $1.28{ }^{\circ} \mathrm{C} \mathrm{min}^{-1}$ due to the high electrical resistance $[18,19]$. Since the electrical conductivity and the heat capacity of the material affect the heating rate, the exothermic properties may vary depending on length and content of CFs, polymer content, and sheet resistance. Therefore, it is necessary to optimize the temperature and rate of temperature increase by identifying the factors that influence the exothermic properties and to analyze the energy conversion efficiency of the heat generating sheet exhibiting a high temperature increase rate. A CF heating sheet requires thermal stability and
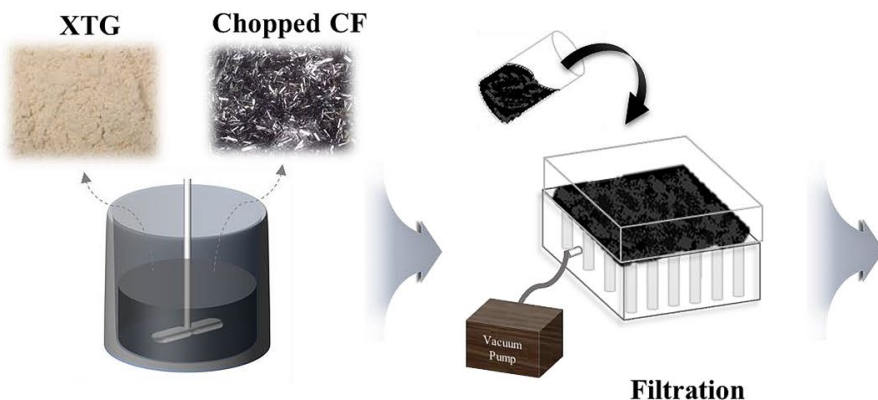
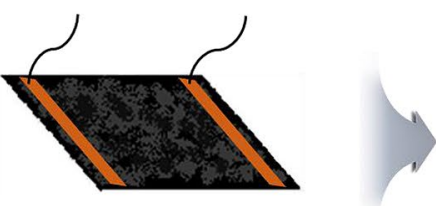

Drying \& Contacts formation mechanical strength above $40^{\circ} \mathrm{C}$. Therefore, it is necessary to investigate the thermal characteristics.

In this study, we developed a CF planar heating element capable of fast heating rate and low voltage driving by factor optimization. Xanthan gum (XTG), which has excellent thermochemical properties and is eco-friendly, was used as an additive [20]. Material content analysis and thermal and mechanical properties of the CF heating sheet were measured by TGA and DMA, respectively, and the mechanism of high thermal conversion efficiency was derived.

\section{Materials and methods}

Polyacrylonitrile (PAN)-based CFs with 12,000 strands were purchased from Toray, Inc., Japan, and cut to various lengths $(2,3,6,9,12$, and $15 \mathrm{~mm}$; chopped CFs) with a cutter. The diameter of each CF strand was approximately $7.5 \mu \mathrm{m}$. XTG, as a dispersing and connecting agent, was purchased from Shinwon Chemicals, China.

Nonwoven fabric sheets were fabricated using chopped CFs and XTG, as follows. First, various dispersant solutions $(1200 \mathrm{~mL}$ ) containing $0.1,0.2,0.4,0.8,1.6$, or $2.4 \mathrm{wt} \%$ XTG were prepared in distilled water and are referred to as 0.1-, 0.2-, 0.4-, 0.8-, 1.6-, and 2.4-XTG, respectively. Subsequently, $0.5 \mathrm{~g}$ of chopped CFs of the desired length was added to the dispersant solution, and the mixture was stirred (HS-100D stirrer, Shinsung Science, South Korea) at $2000 \mathrm{rpm}$ for $1 \mathrm{~h}$. The prepared CF mixture was then poured into a spin-bonded polyester filter (pore size: $300 \mu \mathrm{m}$, filter size: $300 \mathrm{~mm} \times 300 \mathrm{~mm}$ ) equipped with a vacuum pump. The obtained CF sheet was dried in an oven at $90^{\circ} \mathrm{C}$ for $1 \mathrm{~h}$ to remove any remaining water and then trimmed to a size of $250 \mathrm{~mm} \times 250 \mathrm{~mm}$. The schematic representation for fabrication of CF sheets is given in Fig. 1 .

The average thickness of the sheets obtained using CFs of $6 \mathrm{~mm}$ in length was measured using a micrometer $(32 \pm 4.5,56 \pm 4.4,67 \pm 3.9,78 \pm 3.2,83 \pm 3.5$, and $101 \pm 2.5 \mu \mathrm{m}$ for $0.1-, 0.2-, 0.4-, 0.8-, 1.6-$, and 2.4-XTG, respectively). To measure the heating characteristics of

Fig. 1 Schematic representation of fabrication process of CF sheets 
the sheet, copper tape with an acrylic adhesive consisting of carbon black and a conducting polymer was attached to each side. The copper tape was purchased from Shinwha Intertek, South Korea. Copper wires were soldered onto each copper tape, which allowed the voltages to be applied using a DC power supply (MK3305D, MK POWER, China).

The surface and volume resistivities of the CF sheets were measured using a four-point probe (Loresta-GX MCPT700, Mitsubishi Chemical Analytech, Japan). The probe diameter was $2 \mathrm{~mm}$, and the distance (edge to edge) between the probes was $5 \mathrm{~mm}$. The weight fraction of XTG in the CF sheets was measured using thermogravimetric analysis (TGA; SDT650, TA Instruments, Inc., USA) in the temperature range of $25-900^{\circ} \mathrm{C}$ with a heating rate of $10^{\circ} \mathrm{C} \mathrm{min}^{-1}$ under an air flow rate of $20 \mathrm{sccm}$. The tensile strengths of the CF sheets $(25.4 \mathrm{~mm}$ (width) $\times 100 \mathrm{~mm}$ (length) with various thicknesses) were measured using a universal testing machine (LR5K Plus, Lloyd Instruments, UK) according to the ASTM D882 standard. The morphologies of the CF sheets were observed by field emission scanning electron microscopy (FE-SEM; SU8220, Hitachi Inc., Japan). The viscoelastic properties of the CF sheets [6 mm (width) $\times 40 \mathrm{~mm}$ (length) $\times 2 \mathrm{~mm}$ (thickness)] were measured in tensile mode by dynamic mechanical analysis (DMA; Q800, TA Instruments, Inc., USA) in the temperature range of $25-150{ }^{\circ} \mathrm{C}$ with a heating rate of $1{ }^{\circ} \mathrm{C} \mathrm{min}-1$ according to the ASTM D4092-01 and ASTM D 4065-01 standards. The experiments were conducted at a frequency of $1 \mathrm{~Hz}$ with a dynamic displacement of $20 \mu \mathrm{m}$. The far-infrared radiation characteristics of the CF heating sheets $[30 \mathrm{~mm}$ (width) $\times 30 \mathrm{~mm}$ (length) $\times 3 \mathrm{~mm}$ (thickness)] were measured using a Fourier-transform infrared (FT-IR) spectrometer (MIDAC Corp., USA) in the wavelength range of 3-20 $\mu \mathrm{m}$ at temperatures of $37-500^{\circ} \mathrm{C}$ according to the standard measurement method (KFIA-FI-1005). The heating temperature distribution under various applied voltages was monitored using a thermal imaging camera (TXI 6400, Fluke, South Korea), in which the emissivity values obtained from the far-infrared radiation experiment were used as the setting values of the thermal imaging camera.

\section{Results and discussion}

\subsection{Effects of XTG weight fraction and CF length on the surface resistivity $\left(\rho_{s}\right)$ of CF sheets}

To examine the effects of XTG content in the dispersant solution and CF length on the $\rho_{\mathrm{s}}$ of the CF planar sheets, heating sheets were prepared with various CF lengths (2-15 mm). Figure 2 shows that the $\rho_{\mathrm{s}}$ values of the

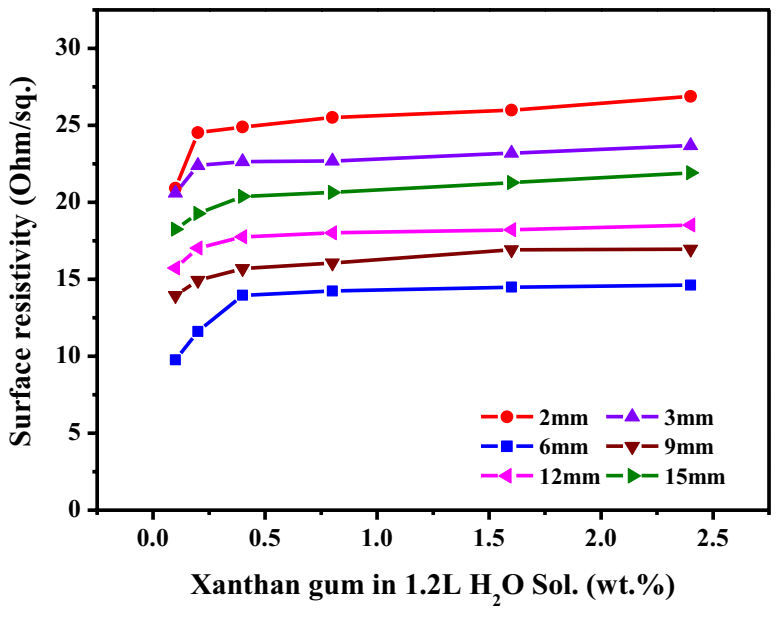

Fig. 2 Surface resistivities of heating sheets prepared using CFs of different lengths as a function of amount of XTG in solution

prepared sheets (average of 10 measurements) increased as a function of XTG content in the dispersant solution. When the XTG weight fraction in the dispersant solutions increased from 0.1 to $2.4 \mathrm{wt} \%$, the $\rho_{\mathrm{s}}$ values of the CF sheets with 2-mm-long CFs increased from 20.91 to $26.87 \Omega \mathrm{sq}^{-1}$. Similar trends for $\rho_{\mathrm{s}}$ as a function of amount of dispersant were observed for all CF lengths, but the lowest $\rho_{\mathrm{s}}$ value was obtained when CFs of $6 \mathrm{~mm}$ in length were used.

Short CFs (length $<6 \mathrm{~mm}$ ) can be easily dispersed, even in low-concentration dispersants (0.1-XTG solution), owing to their low aspect ratios. However, there are many electrical contact points between short CFs, which results in a high $\rho_{s}$. As the weight fraction of dispersant in the solution increases, the amount of dispersant to be coated on the short CFs increases, thereby increasing $\rho_{s}$.

In contrast, long CFs of $9 \mathrm{~mm}$ or more in length are less dispersed in 0.1-XTG solution owing to entanglements between CFs with high aspect ratios, which also results in high $\rho_{s}$. As the concentration of dispersant increases, the $\rho_{\mathrm{s}}$ of the sheet increases owing to an increase in amount of dispersant coated on the surface, although dispersion of long CFs is increased. In this experiment, the optimum CF length was $6 \mathrm{~mm}$. As the content of XTG increased, $\rho_{\mathrm{s}}$ increased, but the deviation decreased. The values and uniformity of $\rho_{\mathrm{s}}$ for CF length and XTG content are shown in Table 1.

\subsection{Actual weight fraction of XTG in CF sheets}

The residual weight of dispersant in the CF sheets may differ from its weight in the dispersion solution, because some of the dispersants are washed out during filtration. 
Table 1 Surface resistivity $\left(\rho_{s}\right)$ values of heating sheets with different CF lengths and XTG weight fractions

\begin{tabular}{|c|c|c|c|c|c|c|}
\hline \multirow{2}{*}{$\begin{array}{l}\text { XTG in sol. } \\
\text { (wt\%) }\end{array}$} & \multicolumn{6}{|c|}{ CF length (mm) } \\
\hline & 2 & 3 & 6 & 9 & 12 & 15 \\
\hline 0.1 & $20.91 \pm 6.27$ & $20.61 \pm 7.58$ & $9.76 \pm 4.12$ & $13.94 \pm 8.69$ & $15.73 \pm 8.75$ & $18.25 \pm 10.59$ \\
\hline 0.2 & $24.53 \pm 5.24$ & $22.39 \pm 5.56$ & $11.60 \pm 3.75$ & $14.92 \pm 3.65$ & $17.02 \pm 8.45$ & $19.27 \pm 8.34$ \\
\hline 0.4 & $24.89 \pm 4.35$ & $22.65 \pm 2.62$ & $13.96 \pm 3.42$ & $15.70 \pm 2.85$ & $17.76 \pm 3.19$ & $20.39 \pm 2.77$ \\
\hline 0.8 & $25.50 \pm 2.78$ & $22.68 \pm 2.51$ & $14.23 \pm 2.44$ & $16.06 \pm 2.61$ & $18.02 \pm 3.09$ & $20.64 \pm 2.45$ \\
\hline 1.6 & $25.99 \pm 2.52$ & $23.19 \pm 2.29$ & $14.50 \pm 1.61$ & $16.92 \pm 2.25$ & $18.21 \pm 2.45$ & $21.27 \pm 1.87$ \\
\hline 2.4 & $26.87 \pm 1.52$ & $23.69 \pm 2.16$ & $14.62 \pm 1.61$ & $16.96 \pm 1.67$ & $18.53 \pm 1.53$ & $21.92 \pm 1.83$ \\
\hline
\end{tabular}

Units: $\Omega \mathrm{sq}^{-1}$

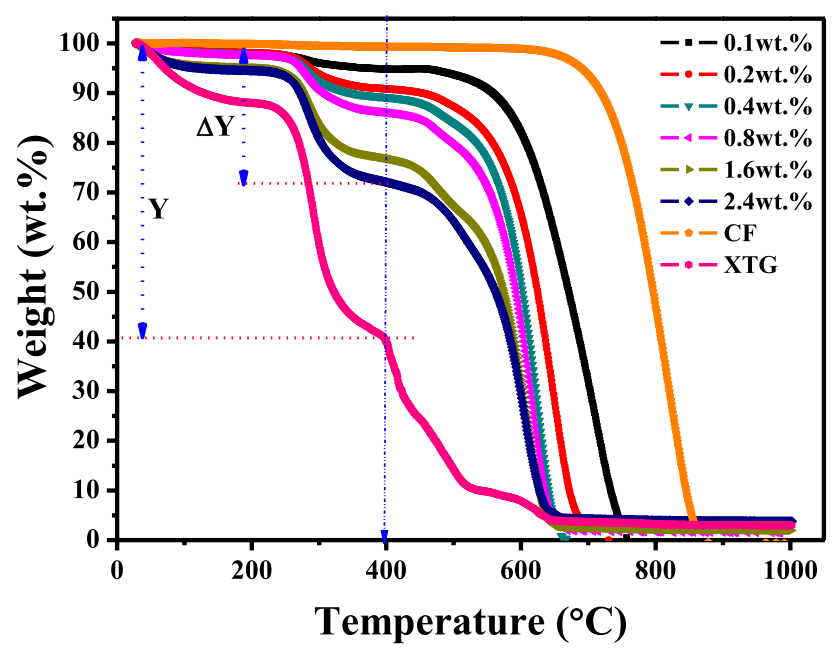

Fig. 3 TGA thermograms for CF sheets prepared with different XTG solutions

The actual weight fraction of XTG in the CF sheets after filtering and drying was measured using TGA. Figure 3 shows the TGA thermograms of CF sheets fabricated using different weight fractions of the dispersant. The labels in the figure correspond to the input weight fractions of XTG in the dispersion solutions. For comparison, the pyrolysis characteristics of raw CF are also shown (orange line, Fig. 3).

CFs are extremely stable at $600{ }^{\circ} \mathrm{C}$ in air but start to decompose above this temperature and are completely combusted by $850^{\circ} \mathrm{C}$. Addition of dispersant to the $\mathrm{CF}$ sheets tends to lower the decomposition temperature. Decomposition of XTG began at approximately $250{ }^{\circ} \mathrm{C}$, and the highest decomposition rate was observed within the temperature range of $250-400{ }^{\circ} \mathrm{C}$.

Based on the TGA data in Fig. 3, the weight fraction of dispersant in the $C F$ sheets was calculated as $\Delta Y / Y$, where $\Delta Y$ is the weight difference between the raw $C F s$ and the dispersant-containing $\mathrm{CF}$ sheet at $400{ }^{\circ} \mathrm{C}$, and $Y$ is the weight difference between the raw $\mathrm{CFs}$ and raw XTG at $400^{\circ} \mathrm{C}$. Notably, the dispersant exhibited a distinguishable weight loss at $400{ }^{\circ} \mathrm{C}$, whereas no change in weight was observed for the CF-only sample. The calculated weight fractions of XTG remaining in the sheets were 7.5, 14.2, $16.9,22.4,37.8$, and $45.8 \mathrm{wt} \%$ for CF sheets prepared using $0.1-, 0.2-, 0.4-, 0.8-, 1.6-$, and 2.4-XTG, respectively. In addition, considering that the density of XTG is $1.5 \mathrm{~g} \mathrm{~cm}^{-3}$, the volume fractions of XTG in the CF sheets were calculated as $9.1,17,20.1,26.4,43$, and 51.2 vol\% for dispersion solutions of $0.1-, 0.2-, 0.4-, 0.8-, 1.6-$, and $2.4-\mathrm{XTG}$, respectively.

\subsection{Electrical and mechanical properties and surface morphologies of CF sheets}

To achieve high electrical conductivity and good mechanical properties, it is necessary to develop nonwoven CF sheets with low electrical volume resistivity $\left(\rho_{\mathrm{v}}\right)$ and high tensile strength. The electrical and mechanical properties of CF nonwoven sheets can be influenced by the amount of XTG as well as the surface morphology. Figure 4 shows the tensile strengths, volume resistivities, and surface morphologies of several types of CF sheets. As shown in Fig. 4a, as the weight fraction of XTG in the CF sheets increased, both the tensile strength and tensile modulus (slope of each plot) increased. This behavior occurred, because the bond strength between randomly oriented CFs was enhanced by the presence of XTG, which increased the elasticity.

Figure $4 \mathrm{~b}$ shows $\rho_{\mathrm{v}}$ (average of 10 measurements) and tensile strength as functions of XTG content. The amount of raw CFs (6 $\mathrm{mm}$ in length) was fixed in all samples. As XTG content increased, tensile strength gradually increased, whereas $\rho_{v}$ was saturated in sheets containing more than $0.8 \mathrm{wt} \%$ of XTG in solution. The measured $\rho_{\mathrm{v}}$ values were 0.06 and $0.13 \Omega \mathrm{cm}$ for CF sheets prepared using 0.2-XTG and 2.4-XTG, respectively. Both the tensile strength and electrical resistivity of the CF sheet prepared using 0.2-XTG were low, because the small amount of XTG in the sheet did not act as a binder and thus did not serve as an electrical insulator (Fig. 3c, d). However, most CFs in the sheet prepared using 2.4-XTG were mechanically connected by and even stacked with XTG, as shown in Fig. 3e, f. This arrangement resulted in high tensile strength and a high $\rho_{\mathrm{v}}$, because XTG acts as both a binder and a resistor. The 

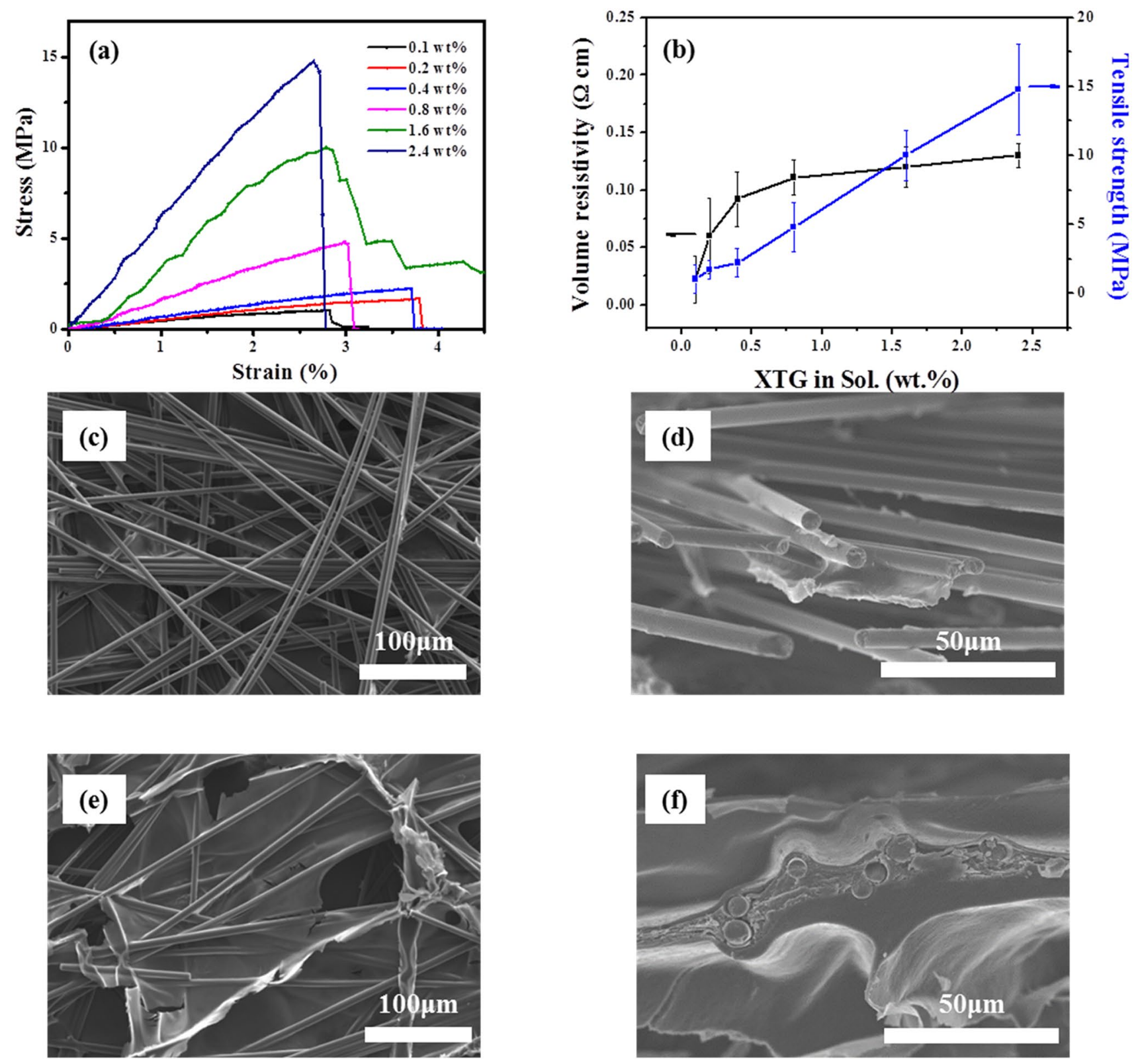

Fig. 4 a Tensile strengths of various CF sheets as a function of strain, $\mathbf{b}$ tensile strength and volume resistivity values of $C F$ sheets as a function of XTG content in solution, c, d SEM images of a CF

addition of more than 2.4 wt $\%$ XTG in solution, however, caused breakage of the sheet during detachment from the filter, resulting in failed measurements of tensile strength and $\rho_{\mathrm{v}}$.

\subsection{DMA of CF sheets}

For general use as portable heating sheets, the variation in mechanical characteristics and electrical properties of $\mathrm{CF}$ sheets should be low at temperatures of $40^{\circ} \mathrm{C}$ or less under bending conditions. In general, a DMA plot provides sheet prepared using $0.2 \mathrm{wt} \% \mathrm{XTG}$, and e, $\mathbf{f}$ SEM images of a CF sheet prepared using $2.4 \mathrm{wt} \%$ XTG

both the storage modulus and loss modulus, as well as a complex modulus $[\tan (\delta)]$. The storage modulus $\left(E^{\prime}\right)$ is due to the elastic nature of the material. The loss modulus $\left(E^{\prime \prime}\right)$ originates from the out-of-phase portion of the response, which reflects the ability of the material to dissipate energy through viscous mechanisms. The $\tan (\delta)$ value of a material can be calculated by dividing the loss modulus by the storage modulus $\left(E^{\prime \prime} / E^{\prime}\right)$, which represents the ratio of the viscous and elastic contributions of the material under the given conditions. In particular, the peak of the $\tan (\delta)$ curve obtained by DMA provides the glass 
transition temperature $\left(T_{\mathrm{g}}\right)$ of a material with high reliability [21].

Figure 5 shows the DMA curves [storage modulus (black line), loss modulus (blue line), and $\tan (\delta)$ (red line)] for a CF sheet produced using 2.4-XTG. While the storage modulus decreases at a constant rate at low temperatures, the rate of change increases at approximately $82^{\circ} \mathrm{C}$, indicating that the CF heating sheet loses its elasticity at this temperature, and flow motion begins. In contrast, the loss modulus continuously increases at low temperatures, reaching a maximum value at approximately $95^{\circ} \mathrm{C}$ owing to slipping of the polymer contained in the CF heating sheet. The tan $(\delta)$ curve shows a maximum value of 0.085 at a temperature of $101.6^{\circ} \mathrm{C}$, which represents the $T_{g}$ of the CF heating sheet, where the ratio between the flow characteristics and elastic characteristics is maximized. The peak of the $\tan (\delta)$ curve corresponds to the energy required to absorb the viscous motions. The CF heating sheet has high elasticity compared with typical epoxy resins, for which values of 0.5-1.5 have been reported [22]. In addition, the uniformity of the system can be confirmed based on the width of the $\tan (\delta)$ peak. A wide $\tan (\delta)$ peak for a CF heating sheet indicates that the width of the system, including the plurality of polymers, is high. In general, a heating sheet should be used at $40^{\circ} \mathrm{C}$ or less to avoid burning human

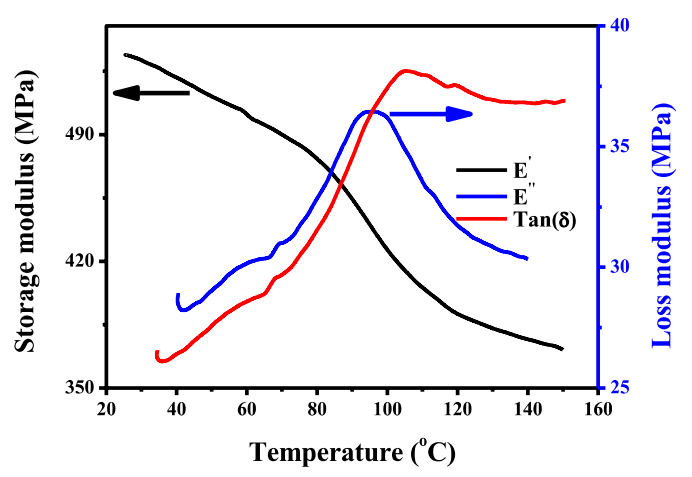

Fig. 5 Dynamic mechanical analysis of a CF sheet prepared using $2.4 \mathrm{wt} \%$ XTG in solution skin. The $T_{\mathrm{g}}$ of $101.6^{\circ} \mathrm{C}$ for the CF heating sheet used in this study implies that this material can be used universally.

\subsection{Far-infrared radiation characteristics of CF sheets}

In general, the electromagnetic wavelength range associated with heat is $4-1000 \mu \mathrm{m}$, which corresponds to the farinfrared region. The optimal wavelength range absorbed by the human body is $5-20 \mu \mathrm{m}$, and a penetration depth up to $2-3 \mathrm{~mm}$ can be achieved in most biological materials $[23,24]$. The far-infrared radiation characteristics of the CF heating sheet, such as emissive power and emissivity, were measured. For comparison, the far-infrared radiation characteristics of a black body and a Ni-Cr material, which is commonly used as a heating element, were also measured.

Figure 6a shows the wavelength-dependent emissive powers measured for a CF heating sheet, a black body, a $\mathrm{Ni}-\mathrm{Cr}$ mesh, and a Ni-Cr plate. All the samples were heated to $60{ }^{\circ} \mathrm{C}$ for measurements. The emissive power of the black body was $52.65 \mathrm{~W} \mathrm{~m}^{-2}$ at a wavelength of $8 \mu \mathrm{m}$ and decreased with increase in wavelength. In the CF heating sheet, the maximum emissive power of $46.0 \mathrm{~W} \mathrm{~m}^{-2}$ was observed at a wavelength of $8.8 \mu \mathrm{m}$. Thus, the emissive power of the CF heating sheet was slightly lower than that of the black body with the emission maximum at a slightly longer wavelength. In contrast, for the $\mathrm{Ni}-\mathrm{Cr}$ mesh and plate, the maximum emissive power was $28.8 \mathrm{~W} \mathrm{~m}^{-2}$ at a wavelength of $9.69 \mu \mathrm{m}$ and $26.25 \mathrm{~W} \mathrm{~m}^{-2}$ at a wavelength of $10.17 \mu \mathrm{m}$, respectively, corresponding to approximately half of the far-infrared emissive power of the CF heating sheet. Thus, the heat radiation efficiency of the CF heating sheet within the far-infrared region is greater than that of $\mathrm{Ni}-\mathrm{Cr}$ materials.

Figure $6 \mathrm{~b}$ shows the emissivity, which was calculated as the ratio of emissive power of the element (CF heating sheet or $\mathrm{Ni}-\mathrm{Cr}$ material) and that of the black body. The emissivity data in the wavelength ranges of $0-5 \mu \mathrm{m}$ and 20-25 $\mu \mathrm{m}$ are not shown, because the signal-to-noise ratio was too high. The emissivities of all the samples increased
Fig. 6 a Emission powers and b emissivity values of a CF sheet, $\mathrm{Ni}-\mathrm{Cr}$ mesh, $\mathrm{Ni}-\mathrm{Cr}$ plate, and black body (note that the emissivity of the black body is 1.0)
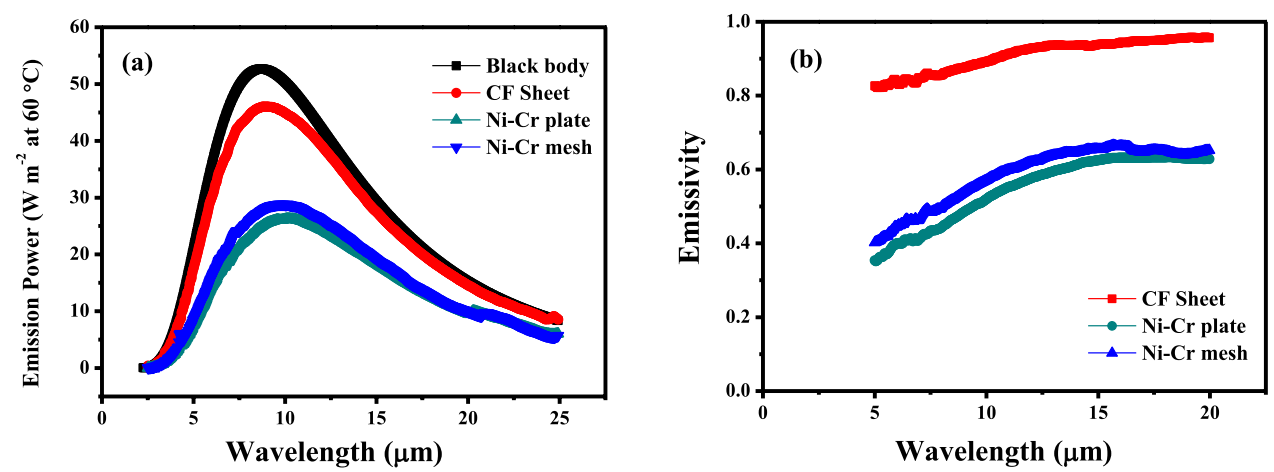
as the wavelength increased. The average emissivity values of the $\mathrm{CF}$ heating sheet, $\mathrm{Ni}-\mathrm{Cr}$ mesh, and $\mathrm{Ni}-\mathrm{Cr}$ plate in the wavelength range of $5-20 \mu \mathrm{m}$ were $0.901,0.534$, and 0.575 , respectively, indicating that the emissivity of the $\mathrm{CF}$ heating sheet is higher than that of the $\mathrm{Ni}-\mathrm{Cr}$ materials. The far-infrared emissivity of the CF heating sheet, 0.901 , was used as the setting value of the thermal imaging camera during measurement of the heat-generation characteristics.

\subsection{Heat-generation characteristics}

Figure 7a shows the heating temperatures of sheets prepared using 0.4-XTG as a function of applied voltage and time. The heating temperatures were recorded at intervals of $5 \mathrm{~s}$ by an infrared camera. The external temperature and volume resistivity of the $\mathrm{CF}$ sheet were $25^{\circ} \mathrm{C}$ and $0.092 \Omega \mathrm{cm}$, respectively. As the voltage applied to the CF sheet increased, the surface temperature of the sheet tended to increase. However, the time required to reach temperature saturation was only $5 \mathrm{~s}$, regardless of the applied voltage. Figure $7 \mathrm{~b}$ shows a 3D photograph and a thermal image acquired using an infrared camera $60 \mathrm{~s}$ after applying a voltage of $5 \mathrm{~V}$. The copper electrodes on both sides of the CF sheet showed remarkably low temperatures, indicating low contact resistance between the electrode and the CF sheet. The maximum, minimum, and average temperatures of the heating sheet are $44.5^{\circ} \mathrm{C}$, $35.2{ }^{\circ} \mathrm{C}$, and $39.8^{\circ} \mathrm{C}$, respectively. Although slight temperature variations occurred depending on the position, overall, the CF surface heating elements exhibited a uniform heating temperature. Notably, conventional linear heating elements, such as $\mathrm{Ni}-\mathrm{Cr}$ wires, use a thick thermal diffusion plate to realize uniform diffusion of the generated heat; therefore, it takes several tens of seconds for the heat to propagate to the outside [25].

Figure $7 \mathrm{c}$ shows the saturation heating temperature after $60 \mathrm{~s}$ as a function of applied voltage for CF sheets prepared using different XTG weight fractions in solution. The higher was the weight fraction of XTG, the lower was the saturation heating temperature, regardless of applied voltage. Wearable heating sheets typically require a portable battery with a $5 \mathrm{~V}$ output, and the heat output must be limited to $40^{\circ} \mathrm{C}$ to prevent burns to the body [26]. The data obtained at an applied voltage of $5 \mathrm{~V}$ (Fig. 7c) show that the CF sheet, when used as a wearable heating sheet, should be prepared using $0.4-2.4$ wt\% XTG in solution. Further, a tensile strength of $2 \mathrm{MPa}$ or more is required for use as a heating sheet. Figures $4 b$ and $7 c$, as well as TGA results in Fig. 3, suggest that the weight fraction of XTG in the CF sheets should be within the range of $16.9-45.8 \mathrm{wt} \%$ for use as portable heating sheets.

Figure $7 d$ shows the heating efficiency of the CF heating sheet manufactured using $0.4-\mathrm{XTG}$ under various applied voltages. The size of the CF heating sheet (excluding the $\mathrm{Cu}$ electrode area) and the resistance were $250 \mathrm{~mm} \times 230 \mathrm{~mm}$ and $2.9 \Omega$, respectively. The electrical powers obtained with applied voltages of $3,5,7,9$, and $12 \mathrm{~V}$ were $3.1,8.6,16.9,27.9$, and $49.7 \mathrm{~W}$, respectively. The conversion efficiency $(\eta)$ of the thermal energy released
Fig. 7 a Variation in temperature over time for a CF sheet prepared using $0.4 \mathrm{wt} \%$ XTG under different applied voltages, b 3D photograph and thermal image of a $\mathrm{CF}$ sheet prepared using $0.4 \mathrm{wt} \%$ XTG produced by an infrared camera after $60 \mathrm{~s}$ under an applied voltage of $5 \mathrm{~V}$, c saturation heating temperature as a function of XTG weight fraction under different applied voltages, and $\mathbf{d}$ heat efficiency of a CF sheet prepared using $0.4 \mathrm{wt} \%$ XTG over time under different applied voltages
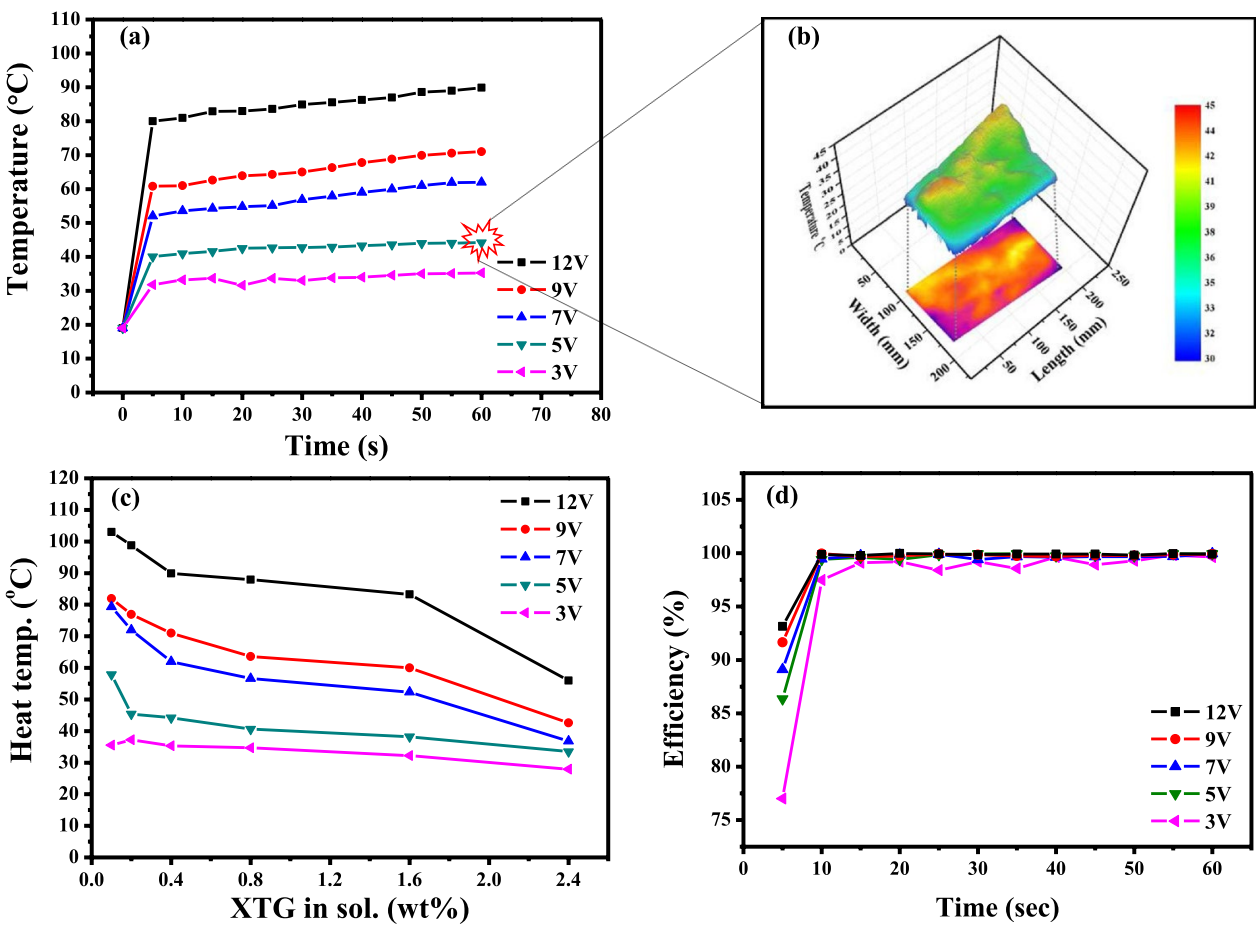

SN Applied Sciences A SPRINGER NatURE journa 
to the surroundings of the heating sheet with respect to the electrical energy input into to the CF heating sheet is expressed by the following equation [18]:

$\eta=\frac{I V \Delta t-C_{\mathrm{p}} m \Delta T}{I V \Delta t}$

where $\Delta T, C_{\mathrm{p}}, m, I$, and $V$ are the change in temperature at time $\Delta t$, the specific heat of the CF sheet, the mass of the CF sheet, the current, and the applied voltage, respectively. The initial efficiency (within $5 \mathrm{~s}$ ) of the heating element increases with applied voltage, and the efficiency reaches $100 \%$ at all applied voltages as heating time increases.

An electric heating sheet must convert input electrical energy into heat energy and transfer it to the surroundings quickly. Some of the input electrical energy increases the internal energy of the heating element, and the remaining energy is transferred to the surroundings in the form of heat energy to raise the ambient temperature. The heat energy efficiency delivered to the surroundings is inversely proportional to the heat capacity of the heating element. That is, the lower are the specific heat and density of the heating element, the faster are the increase in the internal temperature of the heating element and the heat transfer efficiency to the outside. As the amount of input electrical energy increases, the temperature of the heating element increases, resulting in a further increase in heat transfer efficiency owing to a large temperature difference with the surroundings. Considering that the density and specific heat of CFs are $1.86 \mathrm{~g} \mathrm{~cm}^{-3}$ and $0.83 \mathrm{~J} \mathrm{~g}^{-1} \mathrm{~K}^{-1}$ [27], respectively, whereas those of nichrome wire are $8.07 \mathrm{~g} \mathrm{~cm}^{-3}$ and $0.461 \mathrm{~J} \mathrm{~g}^{-1} \mathrm{~K}^{-1}$, the heat capacity per unit volume of CFs is
$1.544 \mathrm{~J} \mathrm{~cm}^{-3} \mathrm{~K}^{-1}$, which is approximately $42 \%$ of the heat capacity of nichrome wire $\left(3.72 \mathrm{~J} \mathrm{~cm}^{-3} \mathrm{~K}^{-1}\right)$.

Figure 8 shows the exothermic diagram of CF planar heating element and $\mathrm{Ni}-\mathrm{Cr}$ linear heating element. When a constant voltage is applied to a unit volume of material, the amount of electrical energy introduced per unit time is inversely proportional to the resistivity of each material. Some of the incoming electric energy increases the internal energy, and the rest increases the external energy to increase the external temperature. When the same voltage is applied to $\mathrm{Ni}-\mathrm{Cr}$ and $\mathrm{CF}$ of unit volume, the volume resistivity of $\mathrm{Ni}-\mathrm{Cr}$ wire $\left(\rho_{\mathrm{M}}\right)$ is $1 / 10$ of that of $\mathrm{CF}\left(\rho_{\mathrm{CF}}\right)$, so the amount of energy flowing into $\mathrm{Ni}-\mathrm{Cr}$ per unit time is large. The heat capacity of $C F\left[C_{p}(C F)\right]$ per unit volume is $40 \%$ of the $\mathrm{Ni}-\mathrm{Cr}$ heat capacity; however, since the amount of energy flowing into $\mathrm{CF}$ per unit time is $1 / 10$ of $\mathrm{Ni}-\mathrm{Cr}$ $\left[C_{\mathrm{P}}(\mathrm{M})\right]$, the internal energy of $C F\left[E_{\mathrm{CF}}(\right.$ Int.) $]$ increases more slowly than that of $\mathrm{Ni}-\mathrm{Cr}\left[E_{\mathrm{M}}(\right.$ Int.) $]$. However, since the heating product using $\mathrm{Ni}-\mathrm{Cr}$ wire diffuses heat to the surrounding area $\left[E_{M}(E x t).\right]$ after local heating of the $\mathrm{Ni}-\mathrm{Cr}$ wire, the increase rate of the ambient temperature per unit time is slow. The CF planar heating element can raise the outside temperature $\left[E_{\mathrm{CF}}(\right.$ Ext.) $]$ more uniformly and faster than the linear heating element due to non-local heating even though the internal energy increase rate is slow.

\section{Conclusion}

In this study, the electrical and mechanical properties and the heat generation characteristics of surface heating elements containing discontinuous CFs were investigated. The $C F$ surface heating elements were prepared by a water

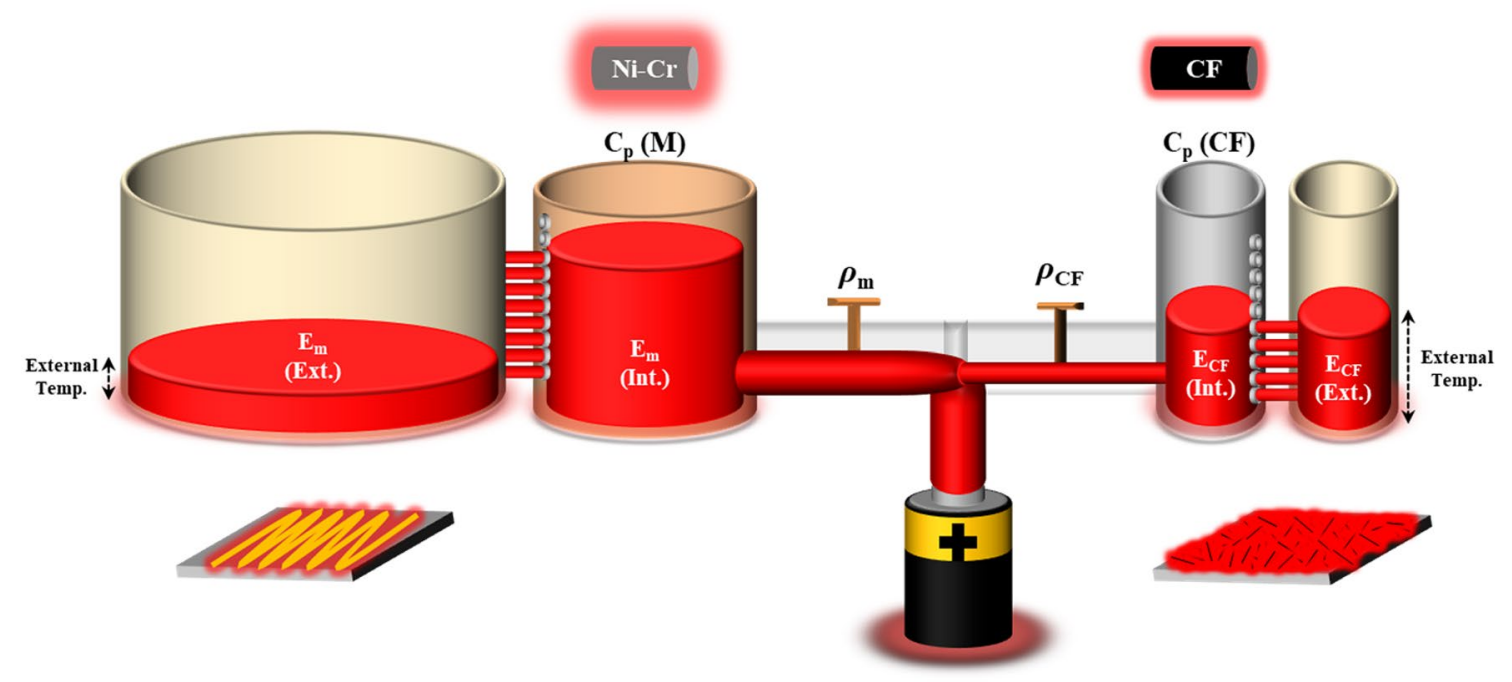

Fig. 8 Heating mechanism of CF sheets 
dispersion method using discontinuous $\mathrm{CFs}$ and a natural binder (XTG), which is not sensitive to the external environment. The effects of the CFs and the binder on the properties of the surface heating elements were determined by varying the $C F$ length and the dispersant content. The heating sheet containing CFs $6 \mathrm{~mm}$ in length showed the lowest surface resistivity; the surface resistivity and tensile strength increased with increasing amount of dispersant. TGA and evaluation of the heat-generation characteristics revealed that the heating sheets containing CFs of $6 \mathrm{~mm}$ in length and XTG contents of 16.9-45.8 wt\% were suitable for commercial requirements. The far-infrared emissivity of the CF heating element was $90 \%$ of that of a black body and considerably higher than that of nichrome wire (55\%). Under various applied voltages, the $\mathrm{CF}$ heating sheet containing 16.9 wt $\%$ XTG reached internal energy saturation within $5 \mathrm{~s}$. This process was rapid owing to the low heat capacity of the CF heating sheet $\left(1.544 \mathrm{~J} \mathrm{~cm}^{-3} \mathrm{~K}^{-1}\right)$. Moreover, the heat conversion efficiency reached $100 \%$ after internal energy saturation. Furthermore, the glass transition temperature of the $\mathrm{CF}$ heating sheet was $101.6^{\circ} \mathrm{C}$. Thus, the CF heating sheet can be used as a portable heating element at required heating temperatures of $40^{\circ} \mathrm{C}$ or less. The CF heating elements can be enlarged by a non-woven fabric manufacturing equipment, so it can be applied to various civilian products, such as heating clothes, electric blankets, and seat heaters for electric vehicles, and military products such as military gloves, combat clothes, fighter planes, and warships. In addition, the CF planar heating element is expected to realize a heating system capable of maximizing energy efficiency when used in combination with a thermal energy storage material such as phase change materials.

Acknowledgements This work was supported by the Civil-Military Technology Cooperation Program (15-CM-MA-14), South Korea.

Author contributions Ji Yeon Kim, So Ra Lee, and Won Seok Kim conceived and planned the experiments. Ji Yeon Kim and So Ra Lee carried out the experiments and contributed to sample preparation. Gyo Woo Lee, Dae Hee Park, Kye Hyeok An, and Won Seok Kim contributed to the interpretation of the results. Ji Yeon Kim and Won Seok Kim took the lead in writing the manuscript. All authors provided critical feedback and helped shape the research, analysis and manuscript.

\section{Compliance with ethical standards}

Conflict of interest The authors declare no conflicts of interest.

\section{References}

1. Cho J-H, Hwang H-S (2018) Image processing technology for analyzing the heating state of carbon fiber surface heating element. J Korea Acad Ind Coop Soc 19:683-688
2. Al-Ghamdi AA, El-Tantawy F (2010) New electromagnetic wave shielding effectiveness at a microwave frequency of polyvinyl chloride reinforced graphite/copper nanoparticles. Compos Part A Appl S 41:1693-1701

3. Rawicz AH (1994) Stress-induced corrosion of wire micro-joints in microelectronics - a quantitative model. Microelectron Reliab 34:875-882

4. Janas D, Koziol KK (2013) Rapid electrothermal response of hightemperature carbon nanotube film heaters. Carbon 59:457-463

5. Yamashita S, Hashimoto K, Suganuma H, Takahashi J (2016) Experimental characterization of the tensile failure mode of ultra-thin chopped carbon fiber tape-reinforced thermoplastics. J Reinf Plast Compos 35:1342-1352

6. Hu X, Tian M, Qu L, Zhu S, Han G (2015) Multifunctional cotton fabrics with graphene/polyurethane coatings with far-infrared emission, electrical conductivity, and ultraviolet-blocking properties. Carbon 95:625-633

7. El-Tantawy F, Kamada K, Ohnabe H (2002) In situ network structure, electrical and thermal properties of conductive epoxy resin-carbon black composites for electrical heater applications. Mater Lett 56:112-126

8. Fischer T, Rühling J, Wetzold N et al (2018) Roll-to-roll printed carbon nanotubes on textile substrates as a heating layer in fiber-reinforced epoxy composites. J Appl Polym Sci 135:45950

9. Isaji S, Bin Y, Matsuo M (2009) Electrical conductivity and selftemperature-control heating properties of carbon nanotubes filled polyethylene films. Polymer 50:1046-1053

10. Bhat G (ed) (2016) Structure and properties of high-performance fibers, 1st edn. Woodhead Publishing, Duxford

11. Farsani RE, Fazaeli R (2012) Applications of carbon fibers produced from polyacrylonitrile fibers. Int J Chem Mat Biomol Sci 6:837-840

12. Morris EA, Weisenberger MC, Abdallah MG et al (2016) Highperformance carbon fibers from very high molecular weight polyacrylonitrile precursors. Carbon 101:245-252

13. Rahaman MSA, Ismail AF, Mustafa A (2007) A review of heat treatment on polyacrylonitrile fiber. Polym Degrad Stab 92:1421-1432

14. Miller GC, Yu J, Joseph RM et al (2017) Melt-spinnable polyacrylonitrile copolymer precursors for carbon fibers. Polymer 126:87-95

15. Zhao RX, Sun P, Liu R et al (2018) Influence of heating procedures on the surface structure of stabilized polyacrylonitrile fibers. Appl Surf Sci 433:321-328

16. Gu Y, Qin X, Li M, Zhang K, Zhang Z (2015) Temperature distribution and curing behaviour of carbon fibre/epoxy composite during vacuum assisted resin infusion moulding using rapid heating methods. Polym Polym Compos 23:11-20

17. Uriya Y, Ikeuchi K, Yanagimoto J (2015) Enhanced formability of thin carbon fiber reinforced plastic sheets in cold/warm embossing with ductile dummy sheets of different thicknesses. Int J Mater Form 8:415-421

18. Kim T, Chung DDL (2003) Carbon fiber mats as resistive heating elements. Carbon 41:2436-2440

19. Rezaei F, Yunus R, Ibrahim NA (2009) Effect of fiber length on thermomechanical properties of short carbon fiber reinforced polypropylene composites. Mater Des 30:260-263

20. Pacheco-Torgal F, Ivanov V, Karak N, Jonkers H (eds) (2016) Biopolymers and biotech admixtures for eco-efficient construction materials, 1st edn. Woodhead Publishing, Duxford

21. Saba N, Jawaid M, Alothman OY, Paridah MT (2016) A review on dynamic mechanical properties of natural fibre reinforced polymer composites. Constr Build Mater 106:149-159

22. Rahul R, Kitey R (2016) Effect of cross-linking on dynamic mechanical and fracture behavior of epoxy variants. Compos Part B Eng 85:336-342 
23. Vatansever F, Hamblin MR (2012) Far infrared radiation (FIR): its biological effects and medical applications. Photonics Lasers Med 1:255-266

24. Brown KJ, Farrelly R, O'Shaughnessy SM, Robinson AJ (2016) Energy efficiency of electrical infrared heating elements. Appl Energy 162:581-588

25. Neves SF, Couto S, Campos JBLM, Mayor TS (2015) Advances in the optimisation of apparel heating products: a numerical approach to study heat transport through a blanket with an embedded smart heating system. Appl Therm Eng 87:491-498

26. Parsons K (ed) (2014) Human thermal environments: the effects of hot, moderate, and cold environments on human health, comfort, and performance, 3rd edn. CRC Press, Boca Raton
27. Callister WD Jr, Rethwisch DG (2000) Fundamentals of materials science and engineering: an integrated approach, 4th edn. Wiley, Hoboken, p 811

Publisher's Note Springer Nature remains neutral with regard to jurisdictional claims in published maps and institutional affiliations. 